\title{
Misperceptions, inactivity and maternal factors may drive obesity among Barbadian adolescents
}

\author{
Pamela S Gaskin ${ }^{1, *}$, Hedy Broome ${ }^{2}$, Colin Alert ${ }^{2}$ and Henry Fraser ${ }^{1}$ \\ 'University of the West Indies, School of Clinical Medicine and Research, Queen Elizabeth Hospital, \\ Bridgetown, Barbados: ${ }^{2}$ Chronic Disease Research Centre, Tropical Medicine Research Institute, Barbados
}

Submitted 5 January 2006: Accepted 31 0ctober 2006: First published online 18 June 2007

\begin{abstract}
Objectives: To describe (1) the prevalence of overweight and obesity and their association with physical activity; (2) the effect of different cut-off points for body mass index (BMI) on weight status categorisation; and (3) associations of weight status with perceptions of body size, health and diet quality.

Design: A cross-sectional study.

Setting: Secondary schools in Barbados.

Subjects: A cohort of 400 schoolchildren, 11-16 years old, selected to study physical education practices.

Results: Prevalence of overweight (15\% boys; $17 \%$ girls) and obesity ( $7 \%$ boys; $12 \%$ girls) was high. Maternal obesity, as defined by the International Obesity Task Force (IOTF) BMI cut-off points, predicted weight status such that reporting an obese mother increased the odds of being overweight by 5.25 ( $95 \%$ confidence interval: $2.44,11.31$ ). Physical activity was inversely associated with weight status; however levels were low. Recreational physical activity was not associated with weight status in either category. Overweight subjects tended to misclassify themselves as normal weight and those who misclassified perceived themselves to be of similar health status to normal-weight subjects. The National Center for Health Statistics and IOTF BMI cut-off points produced different estimates of overweight and obesity.

Conclusions: Our findings suggest that inadequate physical activity and ignorance related to food and appropriate body size are promoting high levels of adiposity with a strong contribution from maternal obesity, which may be explained by perinatal and other intergenerational effects acting on both sexes. Prevalence studies and local proxy tools for adiposity assessment are needed.
\end{abstract}

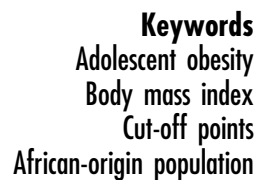

In Barbados, as elsewhere, there is considerable concern over the perceived increasing prevalence of obesity among children and adolescents ${ }^{1-3}$. This predominantly African-origin population is close to the end of the epidemiological nutrition transition. Recently there have been large increases in adult overweight and obesity ${ }^{4-6}$ and concomitant chronic cardiovascular diseases ${ }^{7-10}$. The expectation is that a childhood epidemic will mirror the adult pattern as it has in the developed world ${ }^{11-13}$.

A burgeoning epidemic of childhood and adolescent overweight and obesity is likely to have high $\operatorname{costs}^{14}$ in the vulnerable economic climate that is common in small states. An assessment of prevalence among adolescents is needed.

In addressing this problem, cheap and easy screening is required to identify those most at risk. Selection of appropriate tools is complicated by the fact that most tools in use are proxy measures that do not actually measure adiposity ${ }^{15}$ and vary in validity ${ }^{16}$ depending on the age and ethnicity of the population ${ }^{17}$. Body mass index (BMI) is one such measure ${ }^{1,2}$ where, in addition to the difficulty of selecting appropriate equations for calculating body composition from BMI, there is the added effect of differences in the rate of maturation and its effect on body composition ${ }^{15}$. Importantly, these problems may be exacerbated in transition populations ${ }^{17-19}$ and among the fattest children ${ }^{20}$. Some indication of which set of published cut-off points is the most suitable, in the absence of gold standard measures, would be of use.

It is thought that activity and general fitness in Barbados, as elsewhere, is on the decline among youth ${ }^{21}$ and there is increased access to calories. The exact mechanisms by which obesity develops are complex but some populations are more prone ${ }^{22}$, so that the gene-environment interactions of one group are not necessarily applicable to another ${ }^{23}$. It is therefore important in each population to describe and document the associations of body composition with factors such as family history of obesity, activity 
and food intake for meaningful and effective monitoring when interventions are being planned.

It is clear that, in stemming rising obesity among youth, understanding and responding to nuances in food intake and activity behaviours will be vital, particularly in the adolescent age group known to be heavily influenced by peers $^{24}$. Perceptions among the young in terms of what constitutes good health, overweight and obesity, as well as appropriate physical activity levels, are important factors $^{25,26}$.

The relationship between body image and weight change behaviour and the contradictory findings from different settings ${ }^{27}$ are confusing. These factors have been little explored in Barbados and the Caribbean and similar populations with cultural memory of food insufficiency and debilitating physical labour ${ }^{28}$, but may hold the key to some of the unique drivers of this new scourge of the developing world.

Of interest is the current debate on whether Caribbean women and adolescent girls' belief that 'men prefer their women fat ${ }^{\text {29-31 }}$ contributes to maintaining the preponderance of obesity seen among women ${ }^{5,29}$. This is in striking contrast to the findings in other societies, where girls would expect obesity to have negative social consequences ${ }^{32}$.

In the present study we assessed a sample of subjects aged 11-16 years, aiming to describe the prevalence of overweight and obesity among adolescents and to examine the associations of BMI and weight status, as defined by the International Obesity Task Force (IOTF) BMI cut-off points ${ }^{33}$, with reported structured and recreational activity as well as familial obesity. We also sought to compare the effect of using of different BMI cutoff points, i.e. those of the IOTF and the National Center for Health Statistics (NCHS) ${ }^{34}$, on categorisations of normal weight, overweight and obesity, and examine the associations of weight status and sex with perceptions of body size, health, diet quality, perception or misclassification of weight status and its associations.

\section{Methods}

The sample comprised a cohort of 400 schoolchildren, 11-16 years old, gathered to study physical education (PE) practices and health and fitness among adolescents $^{35}$. School is compulsory in Barbados until age 16 years. At the time of the study approximately $6 \%$ of eligible students were in private schools and were excluded from the sampling frame.

The Barbados Secondary Schools Entrance Examination is a compulsory exam taken in the age group 11-12 years. It is used to rank children for placement in secondary schools. All secondary schools are co-educational except two. Schools were stratified into three categories according to high, medium and low attainment scores, using cut-off marks from the above-mentioned examination. One co-educational school from each stratum was randomly selected. In addition the sole all-girls' school was included in an attempt to determine whether the presence of boys was associated with different female attitudes towards physical activity and self-awareness. One class from each year group comprising five forms was randomly selected from each school. All subjects approached consented to the study.

Weight and height were measured using standard techniques $^{36}$ from which BMI was calculated. A questionnaire on reported age, sex, address, family history of obesity, diabetes and/or hypertension of first-degree relatives and eating and exercise habits was administered to all students in a given school simultaneously, with parental consent.

IOTF BMI cut-off points were used to place students into weight status categories: normal weight, overweight and obese. Maternal, paternal and familial obesity were reported as well as physical activity (structured and recreational). Structured physical activity was measured from responses to the question 'How often do you play an organised sport with an instructor or teacher in charge?' and recreational activity from 'How often do you play a game with friends?' In addition several measures of perception of health and obesity status in the subject, including questions on adequacy of exercise ('enough exercise'), were included.

The study was approved by the Research Ethics Committee of the Ministry of Health and the Environment and the Ministry of Education, Barbados.

\section{Statistical analyses}

Differences in proportions were examined using the $\chi^{2}$ test and mean differences using Student's $t$-test. The simple relationships between weight status (categorised as normal weight and overweight) and sex were examined by univariate linear regression analysis. The health and adiposity indicators in these regression models were health status, diet quality, not having a fat family member, mother or father, engaging in recreational and structured activity and getting enough exercise.

The relationship of BMI to familial (paternal, maternal, other) obesity and physical activity (structured and recreational) was examined by multivariate linear regression analysis, adjusted for age and sex; maternal obesity, paternal obesity, healthy diet, structured activity, recreational activity and 'enough exercise' were offered simultaneously as explanatory variables. The associations of weight status with physical activity, parental obesity and self-perceptions of body size were examined separately by logistic regression analyses adjusted for age. In examining determinants of weight status, the overweight and obesity categories were collapsed. Sex was excluded from the logistic regression model because sex- and age-standardised BMI cut-off points were used 
to establish weight status. For both the linear and the logistic regression analyses, alternative models were tested in which frequency of engaging in 'enough exercise' replaced structured activity. This was done because the frequency of engaging in structured activity was hypothesised to have a different association with body composition from the perception of general fitness, reflected in answers to 'enough exercise', but was likely to be highly correlated with this variable. It was also felt that frequency of structured activity would be more easily assessed by self-reports. Age category was nevertheless included as a covariate as additional effects associated with stage of maturity over the 11-16-year age range might be expected.

The associations of weight status with perceptions of health, quality of food intake and misclassification of weight status were also examined by logistic regression analysis. All results were unweighted.

\section{Results}

\section{Characteristics of subjects}

The sample comprised 236 (59.0\%) girls and 164 boys. The 59 girls from the single-sex school did not differ on any of the anthropometric measures from girls who attended co-educational schools. Data for girls from both types of school were therefore pooled for further analyses. Table 1 shows mean differences in height, weight and BMI by sex. BMI was significantly higher among girls but there was no significant difference in age between the sexes.

\section{Prevalence of obesity}

Twenty-seven per cent of the children were overweight using the IOTF BMI cut-off points. There was no significant sex difference in the prevalence of either overweight or obesity, although these tended to be higher among girls (Fig. 1).

\section{Comparison of IOTF and NCHS BMI cut-off points}

When subjects were categorised as normal weight or not, the proportions in the overweight category were similar for IOTF and NCHS BMI cut-off points (Fig. 2a). However, when the cut-off points were used to separate the over- weight adolescents into obese and overweight groups, the estimates varied widely (Pearson $\chi^{2}=54.09$; $P<0.001)$. The NCHS cut-off points categorised more of the subjects as obese, than as overweight (Fig. 2b). Three per cent of children were categorised as underweight using the NCHS criteria.

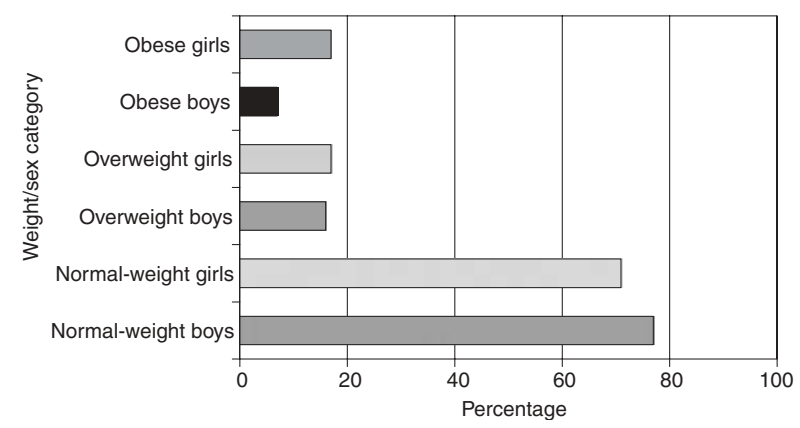

Fig. 1 Weight status of Barbadian adolescents by age and sex. Girls had significantly higher mean body mass index (1.26 $\mathrm{kg} \mathrm{m}^{-2} ; 95 \%$ confidence interval: $\left.0.3,2.2\right)$

a)

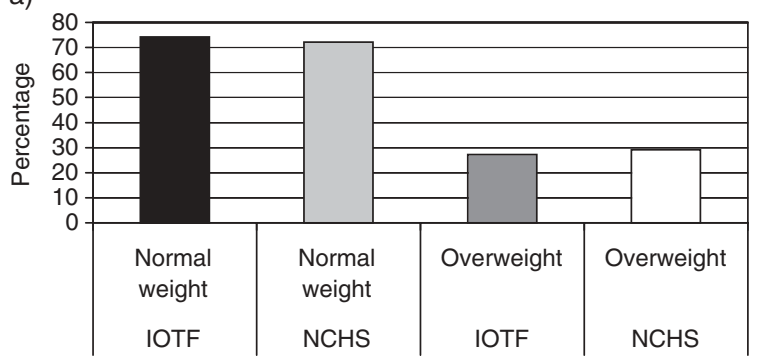

b)

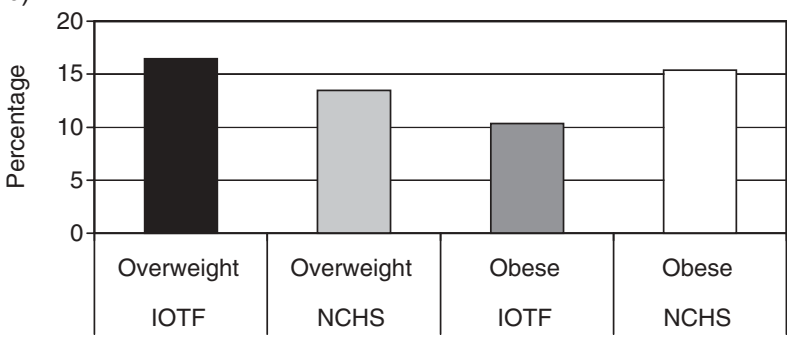

Fig. 2 Comparison of body mass index cut-off points (IOTF International Obesity Task Force; NCHS - National Center for Health Statistics) as measures of overweight and obesity among Barbadian adolescents: (a) comparison of normal weight vs. overweight and obesity; (b) comparison of overweight vs. obesity

Table 1 Characteristics of the subjects in the Barbados Adolescent Health and Fitness Study by sex

\begin{tabular}{lccc}
\hline & Boys $(n=164)$ & All girls $(n=236)$ & $\begin{array}{c}\text { Mean difference }(95 \% \mathrm{Cl}) \\
\text { (boys vs. all girls) }\end{array}$ \\
\hline Age (years), mean \pm SD & $13.30 \pm 1.46$ & $13.22 \pm 1.32$ & $0.076(-0.20,0.35)$ \\
Height $(\mathrm{m})$, mean \pm SD & $1.63 \pm 0.11$ & $1.60 \pm 0.07$ & $0.026(0.01,0.05)^{\star}$ \\
Weight $(\mathrm{kg})$, mean \pm SD & $55.52 \pm 16.30$ & $56.42 \pm 15.01$ & $-1.990(-8.83,4.85)$ \\
BMI $\left(\mathrm{kg} \mathrm{m}^{-2}\right)$, mean \pm SD & $20.52 \pm 4.44$ & $21.76 \pm 5.18$ & $-1.245(-2.22,-0.27)^{\star}$ \\
\hline
\end{tabular}

$\mathrm{Cl}$ - confidence interval; SD - standard deviation; BMI - body mass index.

* Significantly different $(P<0.05)$. 


\section{Associations of BMI and weight status with bealth and obesity-associated indicators}

Health

Among the subjects who answered the question 'Do you think you are healthy?', boys reported being healthy significantly more often than girls. Overweight subjects rated themselves as less healthy (Table 2). The differences between boys and girls in the separate weight status groups were not significant (data not shown). Approximately $19 \%$ of the sample was unable to rate their health status (Table 3).

\section{Diet quality}

There was a tendency for girls and overweight subjects to consider their diet to be unhealthy compared with boys and normal-weight subjects, but neither of these differences was significant (Table 2).

\section{Physical activity}

Most subjects reported some recreational physical activity; 99\% and 93\% among boys and girls, respectively. Boys reported engaging in structured physical activity significantly more often than girls (Table 2). There were

Table 2 Relationship of weight status and sex to health and obesity-associated indicators (males compared with females; normal weight compared with overweight)

\begin{tabular}{llcc}
\hline Reported indicator & \multicolumn{1}{c}{ Factor } & $n$ & OR $(95 \% \mathrm{Cl})$ \\
\hline Health status & Sex & 323 & $1.92(1.08,3.43)$ \\
& Weight status & 323 & $2.05(1.15,3.67)$ \\
Diet quality & Sex & 357 & $1.51(0.99,2.31)$ \\
Fat family member & Weight status & 357 & $1.53(0.95,2.46)$ \\
& Sex & 326 & $1.61(1.03,2.51)$ \\
Fat mother & Weight status & 326 & $2.76(1.66,4.60)$ \\
& Sex & 338 & $1.46(0.74,2.99)$ \\
Fat father & Weight status & 338 & $5.80(2.92,11.53)$ \\
& Sex & 329 & $0.69(0.33,1.43)$ \\
Recreational activity & Weight status & 329 & $0.05(0.99,4.46)$ \\
& Sex & 399 & $6.25(1.42,27.43)$ \\
Structured activity & Weight status & 399 & $1.98(0.57,6.95)$ \\
Enough exercise & Sex & 399 & $4.09(2.58,6.51)$ \\
& Weight status & 399 & $1.47(0.94,2.31)$ \\
& Sex & 399 & $2.49(1.64,3.77)$ \\
& Weight status & 399 & $3.10(1.95,4.94)$ \\
\hline
\end{tabular}

$\mathrm{OR}$ - odds ratio; $\mathrm{Cl}$ - confidence interval.

Table 3 Percentage of subjects who answered 'Don't know' to indicators of health and obesity status

\begin{tabular}{lc}
\hline Variable & $\%(n)$ \\
\hline Health status & $19.0(77)$ \\
Diet quality & $10.8(43)$ \\
Family member's weight status & $18.5(74)$ \\
Maternal weight status & $15.3(61)$ \\
Paternal weight status & $17.0(68)$ \\
Recreational activity & $4.8(19)$ \\
Structured activity & $0.0(0)$ \\
Enough exercise & $9.0(36)$ \\
\hline
\end{tabular}

no significant differences by weight status for either recreational or structured activity.

Enough exercise

Significantly fewer girls (41\%) compared with boys (59\%) thought they got 'enough exercise'. Overweight subjects reported getting 'enough exercise' less frequently than subjects of normal weight status (Table 2). Nine per cent of the sample did not respond to this query.

\section{Familial weight status}

Ten per cent of the sample reported having a fat mother. This comprised $23 \%$ and $24 \%$ of overweight boys and girls, respectively, and 5\% of subjects in the normal weight category. Girls and overweight subjects were more likely to report an overweight family member, while overweight subjects reported a fat mother more frequently. Father's weight status was not significantly related to sex or weight status group (Table 2). Fifteen per cent of the children were unable to categorise their mother's weight status (Table 3).

\section{Determinants of weight status}

In the model which fitted maternal and paternal obesity, healthy diet, structured and recreational activity and enough exercise simultaneously, BMI was significantly and negatively associated with 'enough exercise' and frequency of recreational physical activity and positively with maternal obesity. Structured physical activity was negatively associated, but did not reach significance and was replaced by 'enough exercise' in the model. There were no significant associations of BMI with intake of a healthy diet or with father's fat status.

Similarly, weight status was significantly and negatively associated with 'enough exercise' and positively with maternal obesity. The association with frequency of structured activity was negative but was again significant only at the $10 \%$ level when 'enough exercise' was excluded from the model. No other variables were significantly associated (Table 4). The 59 girls from the single-sex school were removed and these analyses were repeated; the directional relationships remained the same and no relationships lost significance.

Table 4 Determinants of weight status

\begin{tabular}{ll}
\hline Factor & OR $(95 \% \mathrm{Cl})$ \\
\hline Age (continuous) & $1.06(0.90,1.27)$ \\
Maternal weight status (referent: normal) & $5.25(2.44,11.31)$ \\
Father's weight status (referent: normal) & $1.07(0.43,2.60)$ \\
Healthy diet (referent: normal) & $1.13(0.68,1.89)$ \\
Enough exercise (referent: no) & $0.31(0.19,0.53)$ \\
Recreational activity (referent: no) & $0.35(0.09,1.30)$ \\
\hline OR - odds ratio; $\mathrm{Cl}$ - confidence interval. &
\end{tabular}


Table 5 Misclassification of weight status by weight status and sex $(n=359)$

\begin{tabular}{lllr}
\hline Sex & Weight status group (IOTF) & Misclassified & $\%$ \\
\hline Boys & Normal weight & No & 95.1 \\
& & Yes & 4.9 \\
& Overweight & No & 43.3 \\
\multirow{3}{*}{ Girls } & Normal weight & Yes & 56.7 \\
& & No & 95.6 \\
& Overweight & Yes & 4.4 \\
& & No & 38.8 \\
& & Yes & 61.2 \\
\hline
\end{tabular}

IOTF - International Obesity Task Force.

Table 6 Characteristics of subjects who misclassified themselves (males compared with females; normal weight compared with overweight)

\begin{tabular}{lc}
\hline Factor & OR $(95 \% \mathrm{Cl})$ \\
\hline Sex & $1.0(0.5,2.1)$ \\
Weight status & $30.0(14.6,61.5)$ \\
\hline
\end{tabular}

OR - odds ratio; $\mathrm{Cl}$ - confidence interval.

\section{Perceptions of body size}

Three hundred and fifty-nine subjects answered the question 'Are you overweight?' Among those classified as overweight by the IOTF BMI cut-off points, $57 \%$ of boys and $61 \%$ of girls tended to misclassify themselves as normal weight. Few normal-weight subjects, $4.9 \%$ of boys and $4.4 \%$ of girls, classified themselves as overweight (Table 5). Logistic regression analysis revealed that overweight subjects were significantly more likely to misclassify themselves than normal-weight subjects and this was not associated with sex (Table 6).

\section{Overweight subjects who misclassified themselves as normal-weight}

Forty-seven of the subjects who misclassified themselves were overweight. The 13 subjects who wrongly classified themselves as overweight were excluded from analyses pertaining to perceptions and misclassification of weight status as they might be expected to have different reasons for misclassifying. These overweight subjects were then compared with normal-weight subjects on perceptions of diet, health, family history of obesity and frequency of activity. Overweight subjects who misclassified themselves differed from normal-weight subjects only on the greater frequency of reporting a fat mother (odds ratio $=3.59$, 95\% confidence interval (CI): 1.40, 9.19). Notably, mean BMI was $4.43 \mathrm{~kg} \mathrm{~m}^{-2}$ (95\% CI: 2.61, 6.26) lower among these subjects than the mean for the other overweight subjects. In addition, $27 \%$ of the subjects who misclassified themselves were obese compared with 66\% of those who did not (Pearson $\chi^{2}=14.03 ; P<0.001$ ).

\section{Subjects who did not report weight status}

Subjects who were unable to report their own weight status were more likely to be overweight and to think
Table 7 Relationship of health and obesity-associated indicators with reported weight status (subjects who did not report weight status compared with those who did)

\begin{tabular}{ll}
\hline Factor & OR $(95 \% \mathrm{CI})$ \\
\hline Sex & $1.94(0.94,3.40)$ \\
Weight status (measured) & $7.36(3.63,14.93)$ \\
Healthy & $0.20(0.09,0.41)$ \\
Healthy diet & $1.70(0.86,3.38)$ \\
Fat mother & $0.96(0.33,2.86)$ \\
Fat father & $1.79(0.65,4.97)$ \\
Recreational activity & $1.73(0.48,6.25)$ \\
Structured activity & $1.11(0.57,2.17)$ \\
Enough exercise & $0.27(1.30,0.56)$ \\
\hline
\end{tabular}

OR - odds ratio; $\mathrm{Cl}$ - confidence interval.

of themselves as less healthy; they reported getting 'enough exercise' less frequently than those who reported (Table 7). There was, however, no difference in reported consumption of a healthy diet and subjects reported similar amounts of structured activity. They also reported having a fat mother with the same frequency as subjects who reported weight status. There was no association with age. There were no significant differences in BMI or occurrence of obesity in this group compared with other overweight subjects who were able to report their weight status.

\section{Discussion}

Girls were fatter than boys but this is of minimal clinical significance as the prevalence of overweight and obesity was high in both sexes. Nevertheless, there was a nominally higher prevalence of overweight among girls which, because it reflects the adult prevalence patterns ${ }^{3}$, is a trend that should be monitored.

IOTF and NCHS BMI cut-off points gave similar estimates of overweight but gave appreciably different estimates of overweight and obesity when used to separate overweight subjects into these categories. This is an important finding, as both of these proxy tools use the measure BMI as their basis for discrimination. It is established that BMI is a better tool for comparison of body size than for adiposity ${ }^{37,38}$; however, its ease of use and the availability of cut-off points for children based on risk rather than from percentiles ${ }^{33}$ has prompted unguarded use of this tool. Our findings from this study in fat Barbadian secondary-school children, compared with findings from a cohort of relatively thin children ${ }^{17}$ of similar ethnic origin in another setting, reinforce the point that proxy tools such as BMI ought to be used with caution unless validated for a given population. The discrepancy underscores the need to cross-validate BMI and other cheap and easily available proxy measures for fatness with better measures of adiposity, especially where they are to be used for screening in adolescent and child populations ${ }^{37}$. Nevertheless, the distribution of 
weight status using the IOTF cut-off points was close to what would be postulated from other studies and suggests that this instrument probably correlated better with adiposity than the NCHS cut-off points in this group. Underweight was low in this population, likely attributable to a successful nutrition intervention in children $<5$ years old and to increased availability of food.

Boys reported getting enough exercise and engaging more frequently in all types of activity compared with girls. Reported recreational activity was high in both sexes, although only $41 \%$ of girls reported getting enough exercise. The lack of association between recreational physical activity and weight status may therefore result from the avoidance of energy-expensive activities. However, sex differences also may reflect different societal attitudes to the importance of sports for boys and may be one factor promoting a female bias leading to obesity. Our findings were similar to those among black American adolescents of low socio-economic status, where weight status of male adolescents appears to be more related to exercise habits than to television or video game habits and increased participation in high-intensity exercise appears to be important. On the other hand, among the females, neither videos nor exercise habits appear to be related to risk of being overweight ${ }^{39}$. This suggests commonalities that may arise out of historical similarities possibly surrounding negative associations with physical activity.

Subjects who reported getting enough exercise tended to be of normal weight and to have lower BMI. This is in keeping with the results of most published studies ${ }^{40}$ and so lends credibility to the reported answers provided by this group of adolescents. The greater contribution of this variable to explaining weight status when compared with frequency of reported structured activity may reflect a pattern seen in other adolescent groups such that activity provided by PE programmes may have reduced impact because of the small number of students who engage appreciably in such activities ${ }^{41,42}$. School-based physical activity programmes have not been very successful in reducing overweight because, it is thought, of problems with stigma ${ }^{42}$. Our findings nevertheless suggest that adolescents are able to assess what may be adequate levels of exercise. It would be useful to determine the nature of non-PE types of activity as possible avenues for intervention.

Despite the strong suggestion of underreporting of maternal obesity and the likely attenuation of the association from collapsing of the 'Don't know' category with no responses on maternal obesity, it remained a strong predictor of weight status. This points to familial effects that are likely to have both genetic and environmental components, serving to perpetuate the epidemic ${ }^{43}$.

On the measures of perception of health status, a relatively high proportion of subjects were unable to comment on health, diet quality or weight status in themselves. Importantly, among those who gave estimates of diet quality, more than half of the adolescents (more so among overweight girls) thought their diet unhealthy. It is necessary to understand what causes these adolescents to make food choices they deem to be unhealthy, as this would negate any education on good food choices. This is similar to findings from elsewhere ${ }^{44}$. Studies on diet quality and the factors affecting food choices need to be conducted.

Overweight boys and girls were 30 times more likely to misclassify themselves than subjects of normal weight. Our data therefore do not support a sex bias in the misperceptions of weight status. Fifteen per cent of subjects were unable to classify their mother's weight status and reporting of maternal obesity was low compared with the prevalence among Barbadian women ${ }^{5}$. Interestingly, the mean BMI and the frequency of obesity among the overweight subjects misclassifying themselves were significantly lower among those who misclassified than the other overweight subjects. No such differences emerged for subjects unable to report weight status. These factors taken together suggest that the societal definition of overweight does not coincide with that of the scientific community and again speaks to ignorance on appropriate levels of fatness with respect to health risks. A recent study among adults in Barbados supports this, as most obese subjects categorised themselves as overweight or a little fat and most overweight subjects thought themselves a little fat or the right size ${ }^{31}$. We did not analyse whether fatter children had worse social experiences but our data do not suggest that girls see fatter status as more 'normal' for them.

The inability of many subjects to identify healthy states, levels of obesity and adequacy of exercise suggests that ignorance and environmental factors related to adolescence $^{45}$ may be contributing to obesity. Among Barbadian adults there is the suggestion that although there is awareness of the deleterious associations of obesity with health, there is disparity between knowledge and behaviours $^{31}$. Careful research is necessary to clarify what may be subtle differences promoting obesity in some groups in Barbados.

\section{Limitations}

The main limitation of our study is that it is crosssectional. Nevertheless, the abundant data from other studies justifies assumptions on the nature of the relationships. In addition, when examining the determinants of both BMI and weight status the variables measured explained less than $20 \%$ of the variance. This is likely due to the exclusion of factors like food intake and pubertal stage that we did not control for and that are important predictors of body size and adiposity. However, the pattern of relationships of both structured activity and the more vague measure 'enough exercise' with body composition suggests that the finding of no relationship 
between recreational physical activity and body composition reflects the true picture. The improved predictive power of 'enough exercise' in the expected direction compared with frequency of structured activity suggests that there was truthful reporting of perception measures.

Age was reported and so the mid point of each age category (age in years) was used to identify the BMI cut-off point for a given subject. This means that the BMI cut-off point selected for a given subject could have been higher or lower than that which would have been selected if age in months had been recorded. However, the effect of this is unlikely to have been large as children are placed in forms based on age, so that misreporting of age in years would have been unlikely. In addition, the maximum error would have been 6 months for individuals at the extreme of each age category.

Private schools were not included in the sampling frame. These students might be of higher socio-economic status because these schools require fees. However the effect of this, if any, is expected to be negligible because a small percentage of students attend these institutions. In addition, some government support produces a broader socio-economic range of students than might be expected.

This study makes an important contribution, for although it is undoubted that environmental factors underpin the worldwide increase in obesity, the drivers in a given community are clearly highly unique. Our study raises questions about what may be important in the African Diaspora.

\section{Conclusions}

Our findings indicate that Barbadian adolescents are greatly affected by the emerging obesity epidemic, a pattern also seen in adults. This suggests that cultural factors are promoting adiposity, with a strong contribution from maternal obesity, which may be explained by perinatal and other intergenerational effects ${ }^{46,47}$. Our finings do not support the hypothesis that desire to be overweight might be promoting female obesity in this age group, but rather demonstrate misperceptions about weight status in both sexes and of the nutritional value of different foods. There is clear need for identification of the cultural factors, particularly those relating to the adolescent environment, that promote development of obesity in Barbados; for validation of screening tools; and for the establishment of effective education programmes on the desirability and energy cost of activities, food choices and desirable weight status among adolescents.

\section{Acknowledgements}

Sources of funding: There was no source of funding. Conflict of interest declaration: There was no conflict of interest.
Authorship responsibilities: P.S.G. wrote the first draft of the manuscript and was involved in its conception, design and analysis, as well as final approval. H.B. was involved in analysis of the manuscript and in revising it critically for intellectual content, as well as final approval. C.A. designed the original study and gave final approval. H.F. contributed to the design of the original study and gave final approval of the manuscript.

Acknowledgements: The authors are grateful to Dr Lincoln Sargeant who gave comments on an earlier draft of the manuscript.

\section{References}

1 Bjorntorp P. Obesity: a chronic disease with alarming prevalence and consequences. Journal of Internal Medicine 1998; 244: 267-9.

2 Burrows R. [Prevention and treatment of obesity since childhood: strategy to decrease the non transmissible chronic diseases in adult]. Revista Médica de Chile 2000; 128: $105-10$.

3 Fraser H. Obesity: the impact on health and prescription for action In: Morhan $\mathrm{O}$, ed. Health Issues in the Caribbean. Kingston: Ian Randlle, 2005; 199-206.

4 Foster C, Rotimi C, Fraser H, Sundarum C, Liao Y, Gibson E, et al. Hypertension, diabetes, and obesity in Barbados: findings from a recent population-based survey. Ethnicity $\mathcal{E}$ Disease 1993; 3: 404-12.

5 Forrester T, Wilks R, Bennett F, McFarlane-Anderson N, McGee D, Cooper R, et al. Obesity in the Caribbean. Ciba Foundation Symposium 1996; 201: 17-26; discussion 26-31, 32-6.

6 Fraser HS, Forrester T, Wilks R. The obesity epidemic of the Caribbean. West Indian Medical Journal 1996; 45: 1-2.

7 Wilks R, McFarlane-Anderson N, Bennett F, Fraser H, McGee D, Cooper R, et al. Obesity in peoples of the African diaspora. Ciba Foundation Symposium 1996; 201: 37-48; discussion 48-53, 188-93.

8 Leske MC, Wu SY, Hennis A, Connell AM, Hyman L, Schachat A. Diabetes, hypertension, and central obesity as cataract risk factors in a black population. The Barbados Eye Study. Ophthalmology 1999; 106: 35-41.

9 Leske MC, Wu SY, Nemesure B, Li X, Hennis A, Connell AM. Incidence and progression of lens opacities in the Barbados Eye Studies. Ophthalmology 2000; 107: 1267-73.

10 Robinson MT, Fischel-Ghodsian N, Fraser HS, Nicholson GD, Grim CM, Wilson DM, et al. Genetic influences on the increase in blood pressure with age in normotensive subjects in Barbados. Ethnicity \& Disease 2004; 14: $57-63$.

11 Clausen JO, Ibsen H, Ibsen KK, Borch-Johnsen K. Association of body mass index, blood pressure and serum levels of triglycerides and high-density lipoprotein cholesterol in childhood with the insulin sensitivity index in young adulthood: a 13-year follow-up. Journal of Cardiovascular Risk 1996; 3: 427-33.

12 Libman I, Arslanian SA. Type II diabetes mellitus: no longer just adults. Pediatric Annals 1999; 28: 589-93.

13 Merrick J, Birnbaum L, Kandel I, Morad M. Obesity and adolescence. A public health concern. International Journal of Adolescent Medicine and Health 2004; 16: 387-8.

14 Borrell M, Mendez MA, Gros T, de la Figuera M, Davins J, del Amo M, et al. [Analysis of direct costs of controlling arterial hypertension]. Atencion Primaria 1994; 14: 829-34. 
15 Widhalm K, Schonegger K. BMI: does it really reflect body fat mass? Journal of Pediatrics 1999; 134: 522-3.

16 Reilly JJ, Dorosty AR, Emmett PM. Identification of the obese child: adequacy of the body mass index for clinical practice and epidemiology. ALSPAC Study Team. Avon Longitudinal Study of Pregnancy and Childhood. International Journal of Obesity and Related Metabolic Disorders 2000; 24: 1623-7.

17 Gaskin PS, Walker SP. Obesity in a cohort of black Jamaican children as estimated by BMI and other indices of adiposity. European Journal of Clinical Nutrition 2003; 57: 420-6.

18 Walker SP, Gaskin PS, Powell CA, Bennett FI. The effects of birth weight and postnatal linear growth retardation on body mass index, fatness and fat distribution in mid and late childhood. Public Health Nutrition 2002; 5: 391-6.

19 Ghosh A. Receiver operating characteristic (ROC) curve analysis in 5-10-year-old Bengalee girls from Calcutta, India. Annals of Human Biology 2004; 31: 364-9.

20 Cole TJ, Faith MS, Pietrobelli A, Heo M. What is the best measure of adiposity change in growing children: BMI, BMI $\%$, BMI z-score or BMI centile? European Journal of Clinical Nutrition 2005; 59: 419-25.

21 Viikari J. Are our children fit or fat? Acta Paediatrica 2004; 93: 306-7.

22 Tataranni PA, Harper IT, Snitker S, Parigi AD, Vozarova B, Bunt $\mathrm{J}$, et al. Body weight gain in free-living Pima Indians: effect of energy intake vs expenditure. International Journal of Obesity and Related Metabolic Disorders 2003; 27: 1578-83.

23 Phares DA, Halverstadt AA, Shuldiner AR, Ferrell RE, Douglass LW, Ryan AS, et al. Association between body fat response to exercise training and multilocus ADR genotypes. Obesity Research 2004; 12: 807-15.

24 Adams LB. An overview of adolescent eating behavior barriers to implementing dietary guidelines. Annals of the New York Academy of Sciences 1997; 817: 36-48.

25 Kim O, Kim K. Body mass index, body shape satisfaction, and weight control behaviors among Korean girls. Psychological Reports 2005; 96: 676-80.

26 Ichinohe M, Mita R, Saito K, Shinkawa H, Nakaji S, Coombs $\mathrm{M}$, et al. The prevalence of obesity and its relationship with lifestyle factors in Jamaica. Tohoku Journal of Experimental Medicine 2005; 207: 21-32.

27 Kimm SY, Glynn NW, Obarzanek E, Kriska AM, Daniels SR, Barton BA, et al. Relation between the changes in physical activity and body-mass index during adolescence: a multicentre longitudinal study. Lancet 2005; 366: 301-7.

28 Beckles HM. Corporate Power in Barbados: The Mutual Affair: Economic Injustice in a Political Democracy. Bridgetown: Lighthouse Communications, 1989.

29 Tull ES, Butler C, Wickramasuriya T, Fraser H, Chambers EC, Brock V, et al. Should body size preference be a target of health promotion efforts to address the epidemic of obesity in Afro-Caribbean women? Ethnicity \& Disease 2001; 11: 652-60.

30 Simeon DT, Rattan RD, Panchoo K, Kungeesingh KV, Ali AC, Abdool PS. Body image of adolescents in a multiethnic Caribbean population. European Journal of Clinical Nutrition 2003; 57: 157-62.

31 Adams PO, Lynch-Prescod MS, Carter AO. Obesity in primary care in Barbados: prevalence and perceptions. Ethnicity \& Disease 2006; 16: 384-90.
32 Falkner NH, Neumark-Sztainer D, Story M, Jeffery RW, Beuhring T, Resnick MD. Social, educational, and psychological correlates of weight status in adolescents. Obesity Research 2001; 9: 32-42.

33 Cole TJ, Bellizzi MC, Flegal KM, Dietz WH. Establishing a standard definition for child overweight and obesity worldwide: international survey. British Medical Journal 2000; 320: 1240-3.

34 Hamill PV, Drizd TA, Johnson CL, Reed RB, Roche AF. NCHS Growth Curves for Children, Birth-18 years. DHEW Publication No. (PHS) 78-1650. Hyattsville, MD: Department of Health and Human Services, 1977.

35 Alert CV, Holland A, Mellanson-King R, Fraser HS. Physical activity in Barbadian secondary school attenders - results from the Adolescent Health and Fitness Study (AHFIT). West Indian Medical Journal 2000; 49(Suppl. 2): 26.

36 Lohman RG, Roche AF, Martorell R. Anthropometric Standardization Reference Manual. Champaign, IL: Human Kinetics, 1988.

37 McCarthy HD, Cole TJ, Fry T, Jebb SA, Prentice AM. Body fat reference curves for children. International Journal of Obesity 2006; 30: 598-602.

38 Must A, Anderson SE. Body mass index in children and adolescents: considerations for population-based applications. International Journal of Obesity 2006; 30: 590-4.

39 McMurray RG, Harrell JS, Deng S, Bradley CB, Cox LM, Bangdiwala SI. The influence of physical activity, socioeconomic status, and ethnicity on the weight status of adolescents. Obesity Research 2000; 8: 130-9.

40 Salazar-Martinez E, Allen B, Fernandez-Ortega C, TorresMejia G, Galal O, Lazcano-Ponce E. Overweight and obesity status among adolescents from Mexico and Egypt. Archives of Medical Research 2006; 37: 535-42.

41 Salmon J, Timperio A, Cleland V, Venn A. Trends in children's physical activity and weight status in high and low socio-economic status areas of Melbourne, Victoria, 1985-2001. Australian and New Zealand Journal of Public Health 2005; 29: 337-42.

42 Mulvihill C, Quigley R. The Management of Obesity and Overweight: An Analysis of Reviews of Diet, Physical Activity and Behavioural Approaches, 1st ed. London: Health Development Agency, 2003.

43 Dubois L, Girard M. Early determinants of overweight at 4.5 years in a population-based longitudinal study. International Journal of Obesity 2006; 30: 610-17.

44 Hesketh K, Waters E, Green J, Salmon L, Williams J. Healthy eating, activity and obesity prevention: a qualitative study of parent and child perceptions in Australia. Health Promotion International 2005; 20: 19-26.

45 Story M, Neumark-Sztainer D, French S. Individual and environmental influences on adolescent eating behaviors. Journal of the American Dietetic Association 2002; 102: S40-51.

46 Ong KKL, Ahmed ML, Emmett PM, Preece MA, Dunger DB. Association between postnatal catch-up growth and obesity in childhood: prospective cohort study. British Medical Journal 2000; 320: 967-71.

47 Cruickshank JK, Mbanya JC, Wilks R, Balkau B, McFarlaneAnderson N, Forrester T. Sick genes, sick individuals or sick populations with chronic disease? The emergence of diabetes and high blood pressure in African-origin populations. International Journal of Epidemiology 2001; 30: 111-17. 